\title{
Cation Sorption at the Barite (001) and (210)-Water Interfaces
}

JACQUELYN N. BRACCO ${ }^{1}$, SANG SOO LEE ${ }^{2}$, AMANDA DORFMAN $^{1}$, LEXI KENIS ${ }^{1}$, INVA BRAHA ${ }^{1}$, ANDREW G. STACK $^{3}$, AND PAUL FENTER ${ }^{2}$

${ }^{1}$ School of Earth and Environmental Sciences, Queens College, City University of New York, New York, NY, USA. Email: jacquelyn.bracco@qc.cuny.edu

${ }^{2}$ Chemical Sciences and Engineering Division, Argonne National Laboratory, Lemont, IL, USA

${ }^{3}$ Chemical Sciences Division, Oak Ridge National Laboratory, Oak Ridge, TN, USA

Here, we use barite as a model substrate to understand divalent cation interactions with ionic crystals. The coverage and location of either lead $(\mathrm{Pb})$ or strontium $(\mathrm{Sr})$ sorbed to the (001) and (210) surfaces were studied as a function of $[\mathrm{Pb}]_{\mathrm{aq}}$ or $[\mathrm{Sr}]_{\mathrm{aq}}$ using in situ specular x-ray reflectivity (XR) and resonant anomalous $x$-ray reflectivity (RAXR). In the presence of $\mathrm{Pb}$, the XR signals become progressively more distorted as $[\mathrm{Pb}]_{\mathrm{aq}}$ increases, implying the presence of $\mathrm{Pb}$ alters the structure of the two surfaces. In contrast, the presence of $\mathrm{Sr}$ has smaller effects on the XR. The interfacial structural changes imply $\mathrm{Pb}$ and $\mathrm{Sr}$ sorption and that the extent of $\mathrm{Pb}$ sorption may be greater than that of $\mathrm{Sr}$ sorption.

The specific $\mathrm{Sr}$ or $\mathrm{Pb}$ sorption behavior at the (001) and (210) surfaces was measured using RAXR. At both surfaces, $\mathrm{Sr}$ and $\mathrm{Pb}$ incorporate into the topmost barite layer and adsorb inner-sphere with a small outer-sphere fraction. At both surfaces, roughly half the sorbed $\mathrm{Sr}$ is incorporated and the other half is adsorbed, regardless of concentration. $\mathrm{Pb}$ is similarly partitioned half incorporated and half adsorbed at both surfaces at low concentrations $\left([\mathrm{Pb}]_{\mathrm{aq}} \leq 75 \mu \mathrm{M}\right)$, but not at higher concentrations. At $[\mathrm{Pb}]_{\mathrm{aq}} \geq 200-225 \mu \mathrm{M}$, less than a third of the $\mathrm{Pb}$ sorbed to the $(001)$ is incorporated, but up to three-quarters of $\mathrm{Pb}$ sorbed to the (210) is incorporated. The total coverages of $\mathrm{Sr}$ and $\mathrm{Pb}$ at each surface varies depending on concentration. At $[\mathrm{Sr} \text { or } \mathrm{Pb}]_{\mathrm{aq}}=25-75 \mu \mathrm{M}$, the amount of sorbed $\mathrm{Sr}$ or $\mathrm{Pb}$ is $\sim 0.6-1.2 \mathrm{Sr}$ or $\mathrm{Pb}$ per $\mathrm{nm}^{2}$ at the (001) and $\sim 0.4-0.5 \mathrm{Sr}$ or $\mathrm{Pb}$ per $\mathrm{nm}^{2}$ at the (210). At $[\mathrm{Sr} \text { or } \mathrm{Pb}]_{\mathrm{aq}}=200$ $225 \mu \mathrm{M}$, the $\mathrm{Sr}$ coverage is similar to that measured at lower concentrations, but the $\mathrm{Pb}$ coverage is greater: $\sim 2.8 \mathrm{~Pb} / \mathrm{nm}^{2}$ at the (001) and $\sim 1.0 \mathrm{~Pb} / \mathrm{nm}^{2}$ at the (210). At the highest concentration of $\mathrm{Pb}$ measured, $[\mathrm{Pb}]_{\mathrm{aq}}=800-900 \mu \mathrm{M}, \sim 3.9$ $\mathrm{Pb} / \mathrm{nm}^{2}$ sorbs to the (001), while only $\sim 1.9 \mathrm{~Pb} / \mathrm{nm}^{2}$ sorbs to the (210). These results suggest that the (001) has a higher sorption capacity than the (210), despite sorption occurring simultaneously through incorporation and adsorption at both surfaces. 